\section{A comparison of three sub-Tenon's} cannulae

Eye (2004) 18, 1279. doi:10.1038/sj.eye.6701793

Correction to: EYE (2004) 18, 873-876.

doi:10.1038/sj.eye.6701332

Published online 13 February 2004
CM Kumar, C Dodds, H McLure and R Chabria

Following the publication of the above Clinical Study, it has been identified that the Figures 1-3 were not in the correct order. The figures, in the correct order, are reproduced below.

The authors apologise for any confusion this might have caused.

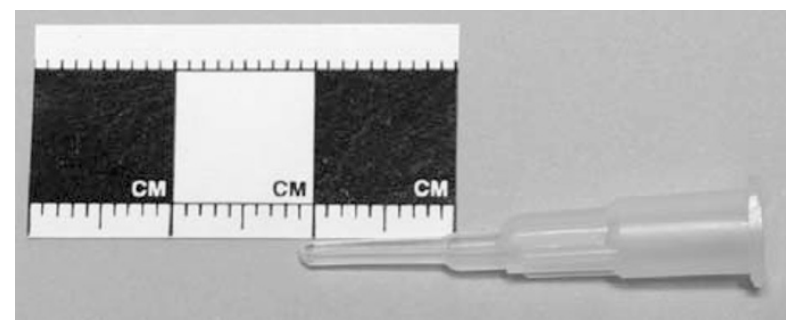

Figure 1 Anterior sub-Tenon's (Greenbaum) plastic cannula $14 \mathrm{G}$ (1.2 cm length).

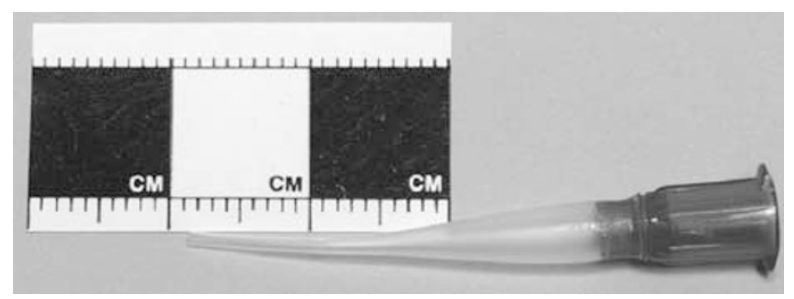

Figure 2 Mid sub-Tenon's (Kumar-Dodds) plastic cannula $22 \mathrm{G}(1.8 \mathrm{~cm}$ length).

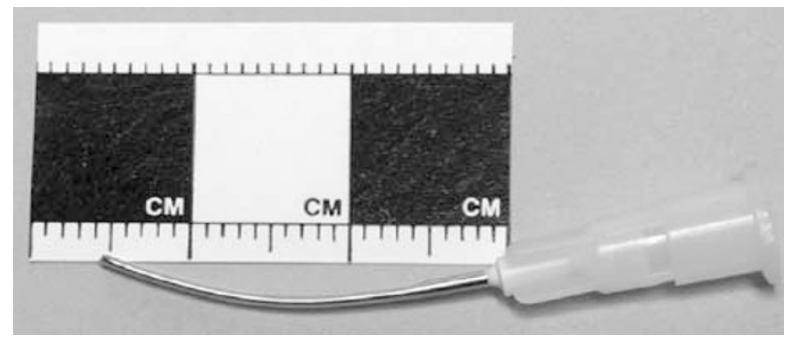

Figure 3 Posterior sub-Tenon's (Stevens) metal cannula 19G (2.5 cm length). 